\title{
Results from the Adverse Event Sedation Reporting Tool: A Global Anthology of 7952 Records Derived from $>160,000$ Procedural Sedation Encounters
}

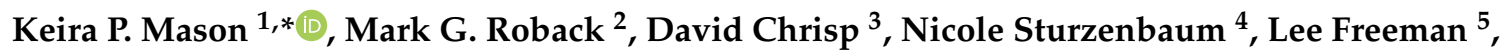 \\ David Gozal ${ }^{6}$, Firoz Vellani ${ }^{7}$, David Cavanaugh ${ }^{8}$ and Steven M. Green ${ }^{9}$ \\ 1 Harvard Medical School, Boston Children's Hospital, Dept. of Anesthesiology, Critical Care and Pain \\ Medicine, 300 Longwood Ave., Boston, MA 02115, USA \\ 2 University of Colorado School of Medicine, Section Head, Emergency Medicine Colorado Children's \\ Hospital, Aurora, CO 80045, USA; Mark.Roback@childrenscolorado.org \\ 3 Tauranga OMS, PO. BOX 15557, 3144 Tauranga, New Zealand; david@taurangaoms.co.nz \\ 4 Toothbeary Richmond, 358a Richmond Road, East Twickenham TW1 2DU, UK; nicole@toothbeary.co.uk \\ 5 Summit Anesthesia Services, 1591 Ridge West Dr., Windsor, CO 80550, USA; lwf1970@gmail.com \\ 6 Department of Anesthesiology and Critical Care Medicine, Hadassah University Hospital, \\ 91120 Jerusalem, Israel; davidgozal@yahoo.com \\ 7 PO Box 792, Cherrybrook, NSW 2126, Australia; firoz04@yahoo.com \\ 8 Boston Biostatistical Consulting, North Reading, MA 01864, USA; dmcav6@gmail.com \\ 9 The Department of Emergency Medicine, Loma Linda University Medical Center, \\ Loma Linda, CA 92354, USA; steve@stevegreenmd.com \\ * Correspondence: keira.mason@childrens.harvard.edu; Tel.: +617-355-5775
}

Received: 16 October 2019; Accepted: 26 November 2019; Published: 1 December 2019

\begin{abstract}
Background: The incidence of sedation-related adverse events, inclusive of both adults and children, administered by multiple specialty providers from different countries and venues, using standardized definitions, has never been reported on an international level. We are reporting the outcome data of the adverse event sedation reporting tool as an important step toward a more complete risk assessment of sedation-related morbidity, mortality, and etiology. The analysis of the AE sedation reporting data include descriptive measures to evaluate the characteristics of the provider, the patient, sedations performed, adverse events, interventions, and outcomes. The primary outcome was the rate and nature of adverse events. Between 12/14/2010 and 12/11/2018 there were 7952 sedations, from an estimated total of 164,114 sedations administered, of which 622 were reported as adverse events. The mean age of the entire patient population is 33.0 years $(0.02-98.7)$. The providers represented 39 countries across six continents. Oxygen desaturation $(75 \%-90 \%)$ for $<60 \mathrm{~s}$ is the most prevalent adverse event with a rate of 7.8 per 10,000 , followed by airway obstruction at a rate of 5.42 per 10,000 . Apnea occurred at a rate of 4.75 per 10,000 . Significant predictors of adverse events are $\geq$ ASA score III ( $p=0.0003)$, procedure time $(6: 00$ pm-12:00 am: $p<0.0001,12: 00-6: 00$ am: $p=0.0003)$, and non-hospital location $(p<0.0001)$. The AE sedation reporting tool has demonstrated that the majority of adverse events in children and adults who receive procedural sedation from multi-specialists internationally required minor interventions and had outcomes of minor risk.
\end{abstract}

Keywords: adults; pediatrics; safety; sedation; children

\section{Introduction}

Procedural sedation, for both adults and children, encompasses a wide range of patients, procedures, venues, and specialty providers. The collecting of sedation outcomes can be challenging, 
as it requires vigilant need to identify, report, and document multiple identifiers. To date, there is a paucity of large scale reports of sedation outcome. The large scale studies in the literature are generally limited to a single patient population (adult, pediatric), sedation provider (pediatrician, dentist, emergency medicine, anesthesia, nursing), sedation technique (medication, route, delivery method), venue (academic or non-academic setting, dental office, hospital based, non-hospital based), procedure (endoscopy, magnetic resonance imaging), and country (United States, Europe, Asia) [1-21]. The largest scale studies to date have reported outcomes from adults in either Europe or the United States who received procedural sedation for gastrointestinal endoscopic procedures [13,22-24].

This report is the first to present the incidence of adverse events, collectively for both adults and children, for sedation delivered by multiple specialty providers performing a wide range of procedures in different countries and venues. The adverse event (AE) sedation reporting tool was published online in 2011 (www.AESedationReporting.com) and published as a manuscript in 2012, as the first tool in existence which would standardize the reporting and tracking of all sedation-related adverse events [25]. It has since been accepted and adopted as a means for sedation providers worldwide to objectively identify sedation-related outcomes [26-34]. As a web-based, free-of-charge tool for which each user has his own password to access and log-in his/her data which is void of HIPAA identifiers, the $\mathrm{AE}$ sedation reporting tool is a valuable means to collect and track data. By identifying and analyzing important demographics and outcomes from each sedation encounter, this tool can provide a benchmark for defining the occurrence and predictors of adverse events across continents, patient populations, procedures, venues, and providers. We are presenting all of the outcome data entered into the www.AESedationReporting.com website by providers worldwide. This database for sedation-outcome reporting supports the collection and sharing of data. The goal of this manuscript is to evaluate the adverse event sedation reporting data in order to determine whether there are any risk factors or predictors of adverse events. This is the first report of adverse event sedation data collected using this AE reporting tool, with international contributions of multi-specialists providing care of adult and pediatric populations. This report is an important first step toward a more complete risk assessment of sedation-related morbidity, mortality, and etiology that could direct efforts to further future safe sedation.

\section{Materials and Methods}

In 2012, an International Sedation Task Force (ISTF) comprised of physicians from 10 specialties to 11 countries (Australia, Brazil, China, Finland, Germany, Israel, Italy, Japan, South Africa, United Kingdom, and United States) presented the adverse event sedation reporting tool as a consensus document intended to standardize the definitions and terminology of sedation related adverse events [25]. The International Sedation Task Force comprised of members from all the continents and we specifically created a tool which would provide simple English and medical terms for the sedation providers to understand. To date we are under the impression that the tool has been translated in paper form to other languages but for online, it remains in English. The ISTF was comprised of sedation providers with established research, clinical experience, leadership, and expertise in the area of procedural sedation. Members were chosen with diverse backgrounds and from diverse specialties (dental medicine and anesthesia, emergency medicine, nursing, hospital medicine, intensive care medicine, anesthesia (physician and nurse), gastroenterology, pediatric medicine). The tool was intended to present a taxonomy of sedation outcomes which would be objective and reproducible. By adopting this taxonomy worldwide, particularly valuable in areas with neither organized sedation systems nor prior means of collecting and reporting their own outcomes, all sedation providers now have a means of tracking and sharing their outcomes through the AE sedation reporting tool database $[26,29,31,34-36]$. This tool is a repository of sedation-related data inputted from all sedation providers worldwide and is a means to report on sedation demographics and outcomes, with the objective of presenting a hierarchical structure to predict the occurrence, risk, and outcome of adverse events (Figure 1, Table 1, Table 2). 

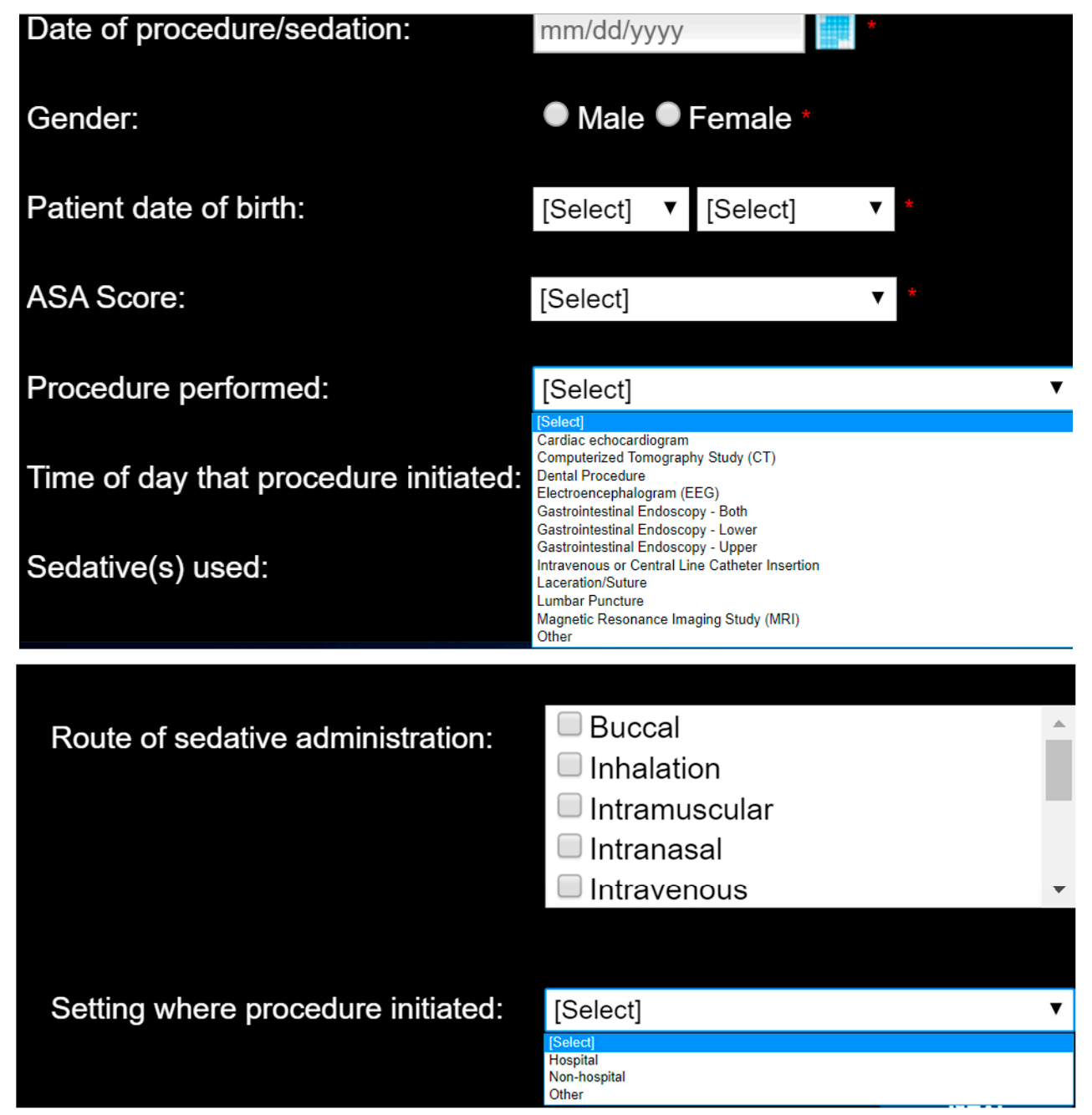

Figure 1. Sedation encounter demographics.

\subsection{Methods}

The AE sedation reporting tool requires individual registration prior to utilization, to collect specifics that include the sedation provider's first and last name, email address, specialty, place and type of practice, educational background, city and country of current practice, phone number and predominant patient population-adult, pediatric, or both. Every time that the registrant logs onto the website to input data, he/she is required to provide an estimate (or update) of the total number of sedations personally performed in a year. The tool consists of contiguous screens, through which the user progresses, each of which requires full completion prior to moving on to the next [25].

The purpose is to identify the occurrence (or non-occurrence) of an adverse event, the urgency of the procedural sedation (emergent versus non-emergent), describe the adverse event using one or more objective, clearly defined descriptors and then in the event an intervention was needed, define what was performed (Figure 2). When entering data, each event and intervention is easily defined for the user, simply by hovering the mouse over the text. Each descriptor is categorized as minimal, minor, or sentinel. The definitions of the interventions performed are standardized and categorized by the risk level of the performed intervention, progressing from minimal (no intervention, antiemetics, antihistamines) to minor (airway repositioning), moderate (mask assisted ventilation), and sentinel (chest compressions). It is not possible to identify which intervention was related to which adverse event when multiple events occurred. Each screen and query must be answered for the user to progress through the reporting tool. 
Table 1. Sedative options on adverse event sedation reporting tool website.

\begin{tabular}{|c|}
\hline Sedative(s) Used \\
\hline Alfentanil (Alfenta, Rapifen) \\
\hline Atropine \\
\hline Chloral hydrate \\
\hline Clonidine \\
\hline Dexamethasone \\
\hline Dexmedetomidine (Precedex) \\
\hline Diazepam (Valium, Antenex) \\
\hline Diphenhydramine (Benadryl, Dimedrol, Daedalon) \\
\hline Diphenhydramine (Benadryl, DPH, DHM, Dimedrol, Daedalon) \\
\hline Epinephrine (adrenaline) \\
\hline Etomidate (Amidate) \\
\hline Fentanyl (Fentanil, Sublimaze, Fentora, Onsolis, Instanyl, Asbtral) \\
\hline Flumazenil (reversal agent for benzodiazepines-flumazepil, Anexate, Lanexat, Mazicon, Romazicon, Anexate) \\
\hline Fosphenytoin (usually used to treat seizures-Cerebyx, Prodilantin) \\
\hline Fospropofol (Lusedra) \\
\hline Ketamine (Ketanest, Ketanest, Ketaset, Ketalar) \\
\hline Ketamine (Ketanest, Ketanest, Ketaset, Ketala) \\
\hline Lidocaine (a local anesthetic-Lignocaine) \\
\hline Lorazepam (Ativan, Temesta) \\
\hline $\begin{array}{c}\text { Meperidine (Demerol, Isonipecaine, Lidol, Pethanol, Piridosal, Algil, Alodan, Centralgin, Dispadol, Dolantin, } \\
\text { Mialgin, Petidin, Dolargan, Dolestine, Dolosal, Dolsin, Mefedina) }\end{array}$ \\
\hline Methohexital (Methohexitone, Brevital) \\
\hline Methylprednisolone (a gluco/corticosteroid-Medrol, Solu-Medrol, Cadista) \\
\hline Metoclopramide (an antiemetic-Maxolon, Reglan, Degan, Maxeran, Primperan, Pylomid, Cerucal, Pramin) \\
\hline Midazolam (Versed, Dormicum, Hypnovel) \\
\hline Morphine (MS Contin, MSIR, Avinza, Kadian, Oramorph, Roxanol, Kapanol) \\
\hline Naloxone (reversal agent for narcotics-Narcan, Nalone, Narcanti) \\
\hline NalTREXone (Revia, Depade, Vivitrol, Bromide) \\
\hline Nitrous oxide \\
\hline Ondansetron (an antiemetic-Zofran) \\
\hline Pentobarbital (Nembutal) \\
\hline Propofol (Diprivan) \\
\hline Remifentanil (Ultiva) \\
\hline Rocuronium (neuromuscular paralytic) \\
\hline Scopolamine (levo-duboisine, hyoscine) \\
\hline Sevoflurane \\
\hline $\begin{array}{c}\text { Succinylcholine (neuromuscular paralytic-Suxamethonium chloride, Suxamethonium, Anectine, Quelicin, } \\
\text { Scoline) }\end{array}$ \\
\hline Sufentanil (Sufenta) \\
\hline
\end{tabular}


Table 2. Route of sedative administration options from adverse event sedation reporting tool website.

\begin{tabular}{c}
\hline Route of Sedative Administration \\
\hline Buccal \\
\hline Inhalation \\
\hline Intramuscular \\
\hline Intranasal \\
\hline Intravenous \\
\hline Oral \\
\hline Other \\
\hline Rectal \\
\hline Subcutaneous \\
\hline Sublingual \\
\hline Topical
\end{tabular}

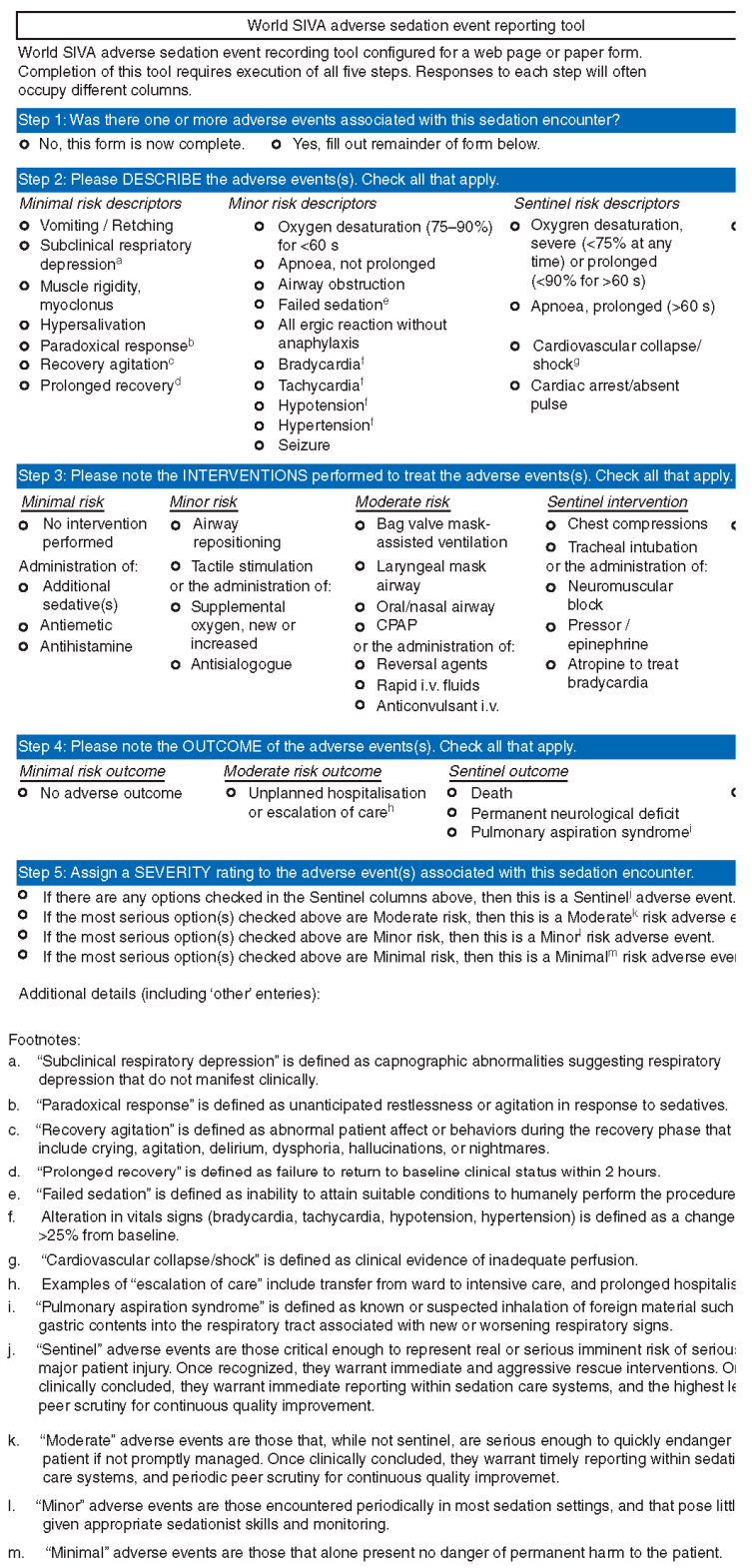

Figure 2. Adverse event sedation reporting tool [25]. 
Outcome measures are categorized as minimal (no adverse outcome), moderate (unplanned hospitalization or escalation of care), or sentinel (death, permanent neurological deficit, or pulmonary aspiration). There may be occasions in which there may be more than one outcome, each with different severity (moderate and sentinel, for example). In this circumstance, the overall severity of the adverse event is assigned a rating (minimal, moderate, sentinel) based on the most severe outcome.

\subsection{Statistical Analysis}

The analysis of the AE sedation reporting data included descriptive measures to evaluate the characteristics of the provider, the patients, sedations performed, interventions, outcomes, and their adverse events. The primary outcome was the rate of adverse events. The secondary outcome was to determine predictor variables of adverse events from sedation.

Incidence rates of adverse events were calculated using the number of events and the estimated number of sedations per year by the provider. Their cumulative sum will be representative of the entire sample of sedation related adverse and non-adverse events. A stratified random re-sampling simulation of non-adverse events based on the distribution of non-adverse events reported was performed to enable further analyses. A multivariate logistic regression model was developed to identify predictors of adverse events. Predictor variables were chosen on the basis of the data (patient and provider) collected: American Society Anesthesiologist (ASA) score, age groupings, gender, time of procedure, and location of procedure. Odds ratios (ORs) and 95\% confidence intervals (CIs) without adjustment for multiple comparisons were considered. $p$-value less than 0.05 were considered statistically significant. All statistical analysis was performed using SAS (version 9.4; SAS Institute, Inc., Cary, NC, USA).

\section{Results}

The data for this study was collected from 12/14/2010 to 12/11/2018 and included 7952 sedation entries, of an estimated 164,114 total sedations performed over this time period. The premise is that from the estimated number of sedations performed each year, there were no adverse events that occurred in the remaining 156,162 cases that did not have data recorded (other than the 622 that were reported in the 7952 cases entered). All sedation entries had complete data points, as every screen must be completed in order for the user to continue data entry in the tool and save the data.

The patient data presented in Table 3 represents their demographic information, with ASA physical status included. The mean age of the entire patient population is 33.0 years (0.02-98.7) years. The majority of adults who receive sedation are between 18 and 70 years of age, with a small minority $(2.2 \%)$ over 80 years of age. The majority of children who receive sedation are between the ages of 3-12 years. Infants less than one year of age are less common, representing $0.6 \%$ of the population overall. The majority of patients $(94.5 \%$ ) are healthy (ASA 1 or 2$)$, presenting for sedation for non-emergent procedure. Those procedures that are considered to be emergent, are most likely to be in healthy patients with ASA $\leq 2(96.3 \%)$.

The providers (users of the AE sedation-reporting tool) represent a mixture of physician (MD, DO, DMD) and non-physician professions from 39 countries across six continents (Figure 3). Physicians are the most common $(79.1 \%)$ providers and include anesthesiologists, dental medicine, emergency medicine, hospital medicine, and pediatricians from 39 countries. There is a vast worldwide presence of AE Tool sedation providers. Europe represents $31.3 \%$ of the sedations, followed by North America $(30.31 \%)$, and Asia (22.8\%). Figure 3 shows a pie chart for the provider's continent of origin, showing the diverse locations for the providers. The providers are from various backgrounds with respect to the academic or non-academic setting, hospital or out-of-hospital setting, and their patient population (adult and/or pediatric). Table 4 shows the country, place of practice, and academic or non-academic setting, where the sedations were performed. Within a country and place of practice, there is a range of one sedation performed to 3328 performed compromising of $0.01 \%$ and $42.2 \%$, respectively. Most sedations are administered in a hospital-based setting $(75.8 \%)$, with a slight propensity toward the 
academic $(44.4 \%)$ versus non-academic setting (35.3\%). Nearly a similar proportion of providers practice adult medicine $(41.5 \%)$ compared to pediatric ( $<18$ years old) medicine $(36.9 \%) .21 .6 \%$ of providers deliver sedation to both the adult and pediatric population. Interestingly, the distribution of adult versus pediatric sedations is nearly similar at $50.9 \%$ and $49.1 \%$, respectively. The most frequently used sedative route is intravenous $(87.2 \%)$, followed by inhalation $(7.2 \%)$, and oral $(2.4 \%)$.

Table 3. Patient demographic and descriptive data of $n=7952$ sedation records.

\begin{tabular}{ccc}
\hline Category & Frequency & Percent \\
\hline Female & 4335 & 54.9 \\
Male & 3569 & 45.2 \\
$<1$ year & 48 & 0.6 \\
$1-3$ & 279 & 3.5 \\
$3-5$ & 972 & 12.3 \\
$5-12$ & 1050 & 13.3 \\
$12-18$ & 437 & 5.5 \\
$18-50$ & 2734 & 34.6 \\
$50-70$ & 1685 & 21.3 \\
$70-80$ & 527 & 6.7 \\
$\geq 80$ & 172 & 2.3 \\
ASA Physical Status & & \\
1 & 4901 & 62.0 \\
2 & 2708 & 34.3 \\
3 & 290 & 3.7 \\
4 & 4 & 0.1 \\
5 & 1 & 0.0 \\
ASA $\leq 2$ (not emergent) & 7470 & 94.5 \\
ASA $>2$ (not emergent) & 279 & 3.5 \\
ASA $\leq 2$ (emergent) & 139 & 1.8 \\
ASA $>2$ (emergent) & 16 & 0.2 \\
\hline
\end{tabular}

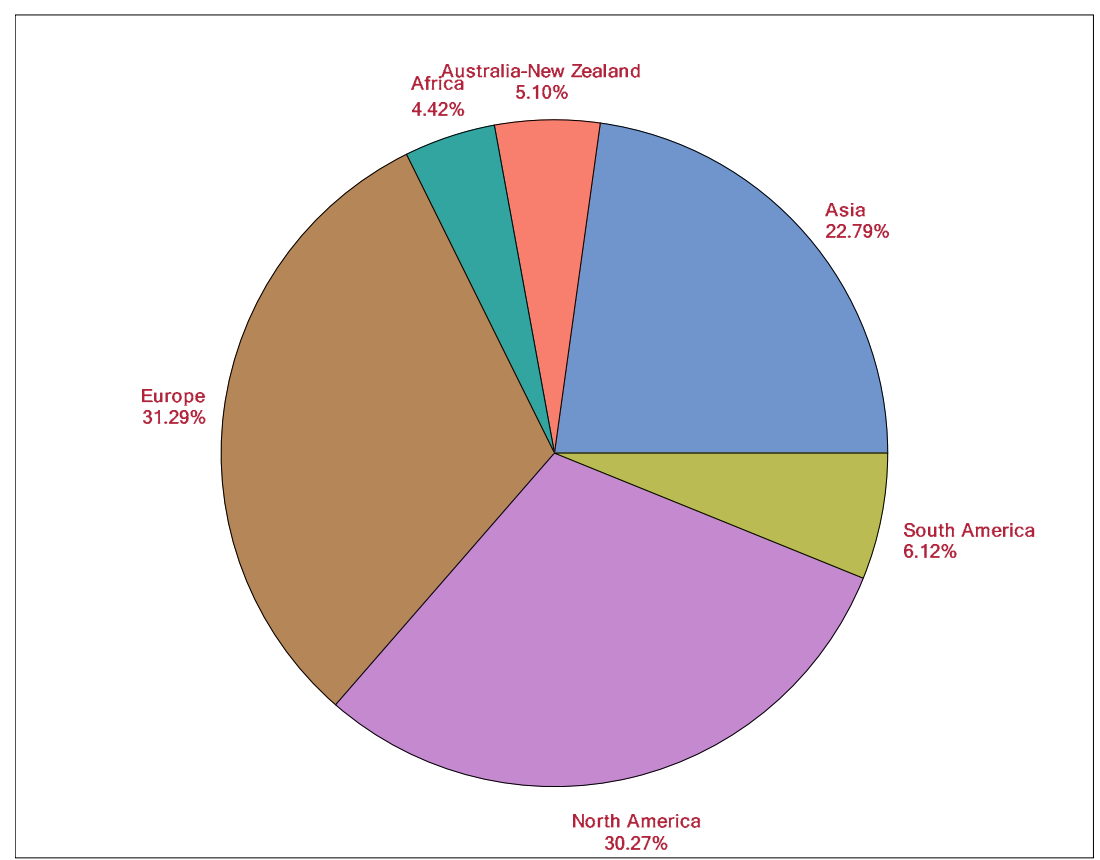

Figure 3. Legend: Distribution of provider's continent of origin $(n=306)$. 
Table 4. Frequency of sedations by provider country and place of practice.

\begin{tabular}{|c|c|c|c|}
\hline Country & Place of Practice & $\begin{array}{c}\text { Academic or } \\
\text { Non-Academic Setting }\end{array}$ & Frequency $n(\%)$ \\
\hline New Zealand & Non-hospital based & Non-Academic & $3328(42.19)$ \\
\hline Australia & Non-hospital based & Non-Academic & $1436(18.20)$ \\
\hline UK & Non-hospital based & Non-Academic & $958(12.15)$ \\
\hline USA & Non-hospital based & Non-Academic & $641(8.13)$ \\
\hline South Korea & Hospital-based & Academic & $415(5.26)$ \\
\hline New Zealand & Both & Both & $365(4.63)$ \\
\hline USA & Hospital-based & Academic & $305(3.87)$ \\
\hline Israel & Hospital-based & Academic & $109(1.38)$ \\
\hline Brazil & Non-hospital based & Academic & $100(1.27)$ \\
\hline India & Hospital-based & Non-Academic & $68(0.86)$ \\
\hline $\mathrm{N} / \mathrm{A}$ & Hospital-based & Academic & $40(0.51)$ \\
\hline India & Hospital-based & Academic & $19(0.24)$ \\
\hline UK & Hospital-based & Both & $19(0.24)$ \\
\hline UK & Hospital-based & Non-Academic & $18(0.23)$ \\
\hline Spain & Hospital-based & Non-Academic & $17(0.22)$ \\
\hline Netherlands & Non-hospital based & Non-Academic & $10(0.13)$ \\
\hline Italy & Hospital-based & Both & $8(0.10)$ \\
\hline Mongolia & Hospital-based & Academic & $4(0.05)$ \\
\hline Netherlands & Hospital-based & Non-Academic & $4(0.05)$ \\
\hline Belgium & Hospital-based & Both & $3(0.04)$ \\
\hline Japan & Hospital-based & Non-Academic & $3(0.04)$ \\
\hline South Korea & Hospital-based & Both & $3(0.04)$ \\
\hline South Africa & Both & Non-Academic & $2(0.03)$ \\
\hline UK & Hospital-based & Academic & $2(0.03)$ \\
\hline Australia & Both & Both & $1(0.01)$ \\
\hline Chile & Hospital-based & Academic & $1(0.01)$ \\
\hline Canada & Hospital-based & Academic & $1(0.01)$ \\
\hline India & Hospital-based & Both & $1(0.01)$ \\
\hline $\mathrm{N} / \mathrm{A}^{* *}$ & Non-hospital based * & Non-Academic & $1(0.01)$ \\
\hline New Zealand & Hospital-based & Both & $1(0.01)$ \\
\hline Saudi Arabia & Hospital-based & Both & $1(0.01)$ \\
\hline Saudi Arabia & Non-hospital based & Non-Academic & $1(0.01)$ \\
\hline UK & Both & Both & $1(0.01)$ \\
\hline USA & Hospital-based & Non-Academic & $1(0.01)$ \\
\hline USA & Hospital-based & Both & $1(0.01)$ \\
\hline
\end{tabular}

${ }^{*}$ Non-hospital-based place of practice(s) are generally private practice or clinics. ${ }^{* *} 41$ events had N/A as their country, indicating 'Not available'. These came from four users for which the country of origin USA.

For those patients who experienced adverse events, the summary statistics of their age and age group distribution are mean age is $32.1(0.1-98.7)$ years. Our multivariable model presents 622 adverse events representing outcomes of a total of 164,114 sedations (Table 5). Reference groups are indicated 
for each predictor for which we can compare the other groups against. Several notable predictors were associated with higher risks: ASA score $\geq$ III or higher (OR 1.89), age groups 50-70 (OR 2.19) and 70-80 (OR 2.81), and procedure time occurring between 6:00 pm-12:00 am (OR 8.74) and 12:00-6:00 am (OR 5.86). Predictors of adverse events included ASA score $\geq$ III $(p=0.0003)$, age groups: $1-3(\mathrm{P}=0.0181)$, $3-5(p<0.0001), 50-70(p<0.0001), 70-80(p<0.0001)$, procedure time of 12:00-6:00 pm $(p=0.0027)$, 6:00 pm-12:00 am $(p<0.0001)$, and 12:00-6:00 am $(p=0.0003)$, and non-hospital location $(p<0.0001)$.

Table 5. Multivariable logistic regression model for adverse events.

\begin{tabular}{|c|c|c|c|c|c|}
\hline Variable & Proportion & $n / N$ & Odds Ratio & $95 \%$ CI & $p$-Value \\
\hline \multicolumn{6}{|l|}{ ASA } \\
\hline I or II & 0.006 & 991/159184 & Reference & & \\
\hline III or higher & 0.009 & $46 / 5345$ & 1.89 & $1.34-2.67$ & 0.0003 \\
\hline \multicolumn{6}{|l|}{ Age (year) } \\
\hline$<1$ & 0.049 & $39 / 790$ & 0.99 & $0.54-1.81$ & 0.9678 \\
\hline $1-3$ & 0.020 & $107 / 5317$ & 0.60 & $0.39-0.92$ & 0.0181 \\
\hline $3-5$ & 0.006 & $115 / 20270$ & 0.33 & $0.22-0.49$ & $<0.0001$ \\
\hline $5-12$ & 0.010 & $203 / 21104$ & 1.37 & $0.97-1.94$ & 0.0719 \\
\hline $12-18$ & 0.010 & $86 / 8895$ & 1.09 & $0.71-1.66$ & 0.6986 \\
\hline $18-50$ & 0.003 & $173 / 58458$ & Reference & & \\
\hline $50-70$ & 0.004 & $158 / 35507$ & 2.19 & $1.53-3.13$ & $<0.0001$ \\
\hline $70-80$ & 0.008 & $92 / 10851$ & 2.81 & $1.83-4.32$ & $<0.0001$ \\
\hline$\geq 80$ & 0.019 & $64 / 3337$ & 0.82 & $0.46-1.47$ & 0.5093 \\
\hline \multicolumn{6}{|l|}{ Sex } \\
\hline Female & 0.002 & $184 / 90883$ & Reference & & \\
\hline Male & 0.003 & 231/73024 & 1.13 & $0.82-1.38$ & 0.2492 \\
\hline \multicolumn{6}{|l|}{ Procedure Time } \\
\hline 6:00 am-12:00 pm & 0.002 & 226/114917 & Reference & & \\
\hline $12: 00-6: 00 \mathrm{pm}$ & 0.003 & $152 / 48439$ & 1.40 & $1.12-1.73$ & 0.0027 \\
\hline 6:00 pm-12:00 am & 0.076 & $32 / 420$ & 8.74 & $5.43-14.06$ & $<0.0001$ \\
\hline $12: 00-6: 00 \mathrm{am}$ & 0.038 & $5 / 131$ & 5.86 & $2.24-15.34$ & 0.0003 \\
\hline \multicolumn{6}{|l|}{ Procedure Location } \\
\hline Hospital & 0.017 & $295 / 17152$ & Reference & & \\
\hline Non-hospital & 0.001 & $120 / 146729$ & 0.03 & $0.02-0.04$ & $<0.0001$ \\
\hline Other* & 0.000 & $0 / 26$ & $<0.001$ & NE-NE & 0.9697 \\
\hline
\end{tabular}

* Other could represent office, clinic, ambulatory-based setting. Reference indicates which group we can compare the other groups against.

With regards to significant predictors of age, the odds ratio show that age groups $1-2,3-5$, and $\geq 80$ have lower odds of experiencing an AE than those 18-50 years old. The corresponding results of odds ratio and $95 \% \mathrm{CI}$ is presented visually in Figure 4 . The odds ratio is represented by the colored square and the $95 \%$ CIs are shown as lines for each individual predictor. The predictors that are significant are represented by having the odds ratio and 95\% CI entirely outside of the vertical reference line of 1 .

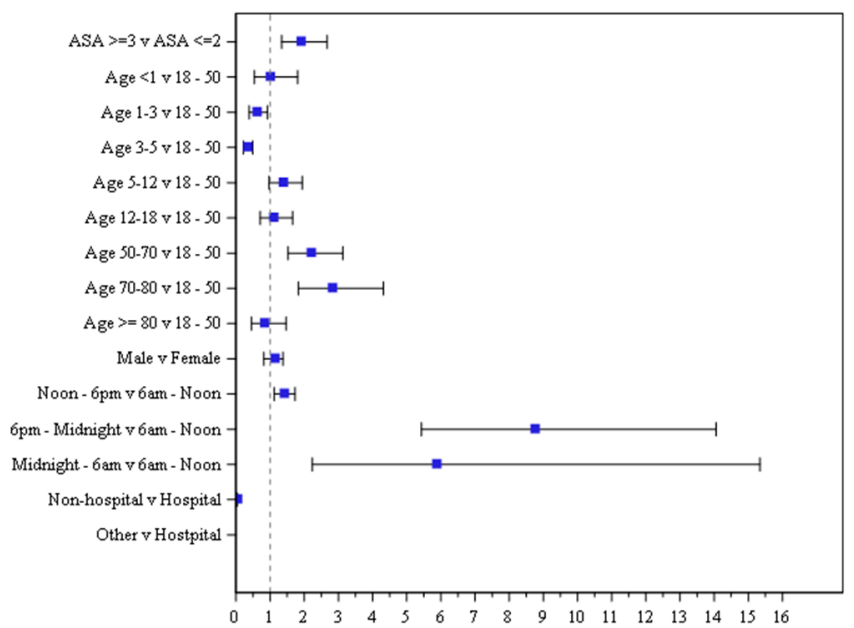

Figure 4. Forest plot depicting odds ratio and 95\% confidence intervals. 
The identification of adverse events by risk descriptors is summarized in Table 6. This includes the risk of adverse events, the interventions performed, their outcomes, and the severity level. The most common sedation risk is at the moderate level (62.5\%). The most common intervention and outcome risk is at the minor level, $59.5 \%$ and $93.4 \%$, respectively. The most common severity is at the moderate level (61.5\%). The sedation risks of adverse events are presented in Table 7. Of the 622 events, there were $94(15.1 \%)$ sentinel events: Oxygen desaturation severe $(<75 \%$ at any time) $(n=63)$, prolonged ( $>60$ s) Apnea $(n=25)$, cardiovascular collapse / shock $(n=3)$, and cardiac arrest/absent pulse $(n=3)$. There were $389(62.5 \%)$ cases of moderate events: Oxygen desaturation $(75-90 \%)$ for $<60 \mathrm{~s}(n=128)$, and airway obstructions $(n=89)$. There were $139(22.3 \%)$ cases of minor events: Vomiting/retching $(n=47)$. There were no cases with minimal risk. No deaths were reported. Sentinel events were analyzed separately to identify predictors of interest with similar results. All sedation providers of sentinel events were contacted to confirm the course and occurrence of events.

Table 6. Identification of adverse events by risk descriptors.

\begin{tabular}{ccccc}
\hline \multicolumn{5}{c}{ Frequency $\boldsymbol{n}(\mathbf{\%})$} \\
\hline & Sedation Risks & Intervention Risks & Outcome Risks & Severity \\
\hline Minimal & 0 & $167(21.7)$ & 0 & 0 \\
Minor & $139(22.3)$ & $457(59.5)$ & $385(93.4)$ & $78(21.0)$ \\
Moderate & $389(62.5)$ & $123(16.0)$ & $15(3.6)$ & $228(61.5)$ \\
Sentinel & $94(15.1)$ & $21(2.7)$ & $12(2.9)$ & $65(17.5)$ \\
Total & $622(19.06)$ & $768(19.06)$ & $412(19.06)$ & $371(19.06)$ \\
\hline
\end{tabular}

Table 7. Incidence of adverse events-risks and rates per 10,000.

\begin{tabular}{|c|c|c|c|c|c|c|c|}
\hline Risks & Minimal & Minor & Moderate & Sentinel & Total $(\%)$ & Rate & $95 \% \mathrm{CI}$ \\
\hline \multicolumn{8}{|l|}{ Sedation Risks } \\
\hline Oxygen desaturation $(75-90 \%)$ for $<60 \mathrm{~s}$ & N/A & 0 & 128 & 0 & $128(20.6)$ & 7.80 & $6.56-9.27$ \\
\hline Airway obstruction & N/A & 0 & 89 & 0 & 89 (14.3) & 5.42 & $4.41-6.68$ \\
\hline Apnea & N/A & 0 & 53 & 25 & $78(12.5)$ & 4.75 & $3.81-5.93$ \\
\hline Oxygen desaturation, severe ( $<75 \%$ at any time) & N/A & 0 & 0 & 63 & $63(10.1)$ & 3.84 & $3.00-4.91$ \\
\hline Vomiting/Retching & N/A & 47 & 0 & 0 & $47(7.6)$ & 2.86 & $2.15-3.81$ \\
\hline Failed sedation & N/A & 0 & 30 & 0 & $30(4.8)$ & 1.83 & $1.28-2.61$ \\
\hline Subclinical respiratory depression & N/A & 29 & 0 & 0 & $29(4.7)$ & 1.77 & $1.23-2.54$ \\
\hline Hypertension & N/A & 0 & 26 & 0 & $26(4.2)$ & 1.58 & $1.08-2.33$ \\
\hline Hypotension & N/A & 0 & 23 & 0 & $23(3.7)$ & 1.40 & $0.93-2.11$ \\
\hline Hypersalivation & N/A & 22 & 0 & 0 & $22(3.7)$ & 1.34 & $0.88-2.04$ \\
\hline Tachycardia & N/A & 0 & 19 & 0 & $19(3.1)$ & 1.16 & $0.74-1.82$ \\
\hline Bradycardia & N/A & 0 & 16 & 0 & $16(2.6)$ & 0.97 & $0.60-1.60$ \\
\hline Paradoxical response & N/A & 14 & 0 & 0 & $14(2.3)$ & 0.85 & $0.51-1.44$ \\
\hline Recovery agitation & N/A & 11 & 0 & 0 & $11(1.8)$ & 0.67 & $0.37-1.21$ \\
\hline Prolonged recovery & N/A & 6 & 0 & 0 & $61.0)$ & 0.37 & $0.16-0.81$ \\
\hline Seizure & N/A & 6 & 0 & 0 & $6(1.0)$ & 0.37 & $0.16-0.81$ \\
\hline Allergic reaction without anaphylaxis & N/A & 0 & 5 & 0 & $5(0.8)$ & 0.30 & $0.13-0.73$ \\
\hline Muscle rigidity, myoclonus & N/A & 4 & 0 & 0 & $4(0.6)$ & 0.24 & $0.09-0.65$ \\
\hline Cardiac arrest/absent pulse & N/A & 0 & 0 & 3 & $3(0.5)$ & 0.18 & $0.06-0.57$ \\
\hline Cardiovascular collapse/shock & N/A & 0 & 0 & 3 & $3(0.5)$ & 0.18 & $0.06-0.57$ \\
\hline Total Sedation Risks & N/A & $\begin{array}{c}139 \\
(22.3 \%)\end{array}$ & $\begin{array}{c}389 \\
(62.5 \%)\end{array}$ & $\begin{array}{c}94 \\
(15.1 \%)\end{array}$ & 622 & & \\
\hline \multicolumn{8}{|l|}{ Intervention Risks } \\
\hline Airway repositioning & 0 & 183 & 0 & 0 & $183(23.8)$ & & \\
\hline Supplemental oxygen, new or increased & 0 & 147 & 0 & 0 & $147(19.1)$ & & \\
\hline Tactile stimulation or the administration of & 0 & 120 & 0 & 0 & $120(15.6)$ & & \\
\hline No intervention performed & 114 & 0 & 0 & 0 & $114(14.8)$ & & \\
\hline Oral/nasal airway & 0 & 0 & 51 & 0 & $51(6.6)$ & & \\
\hline Bag valve mask assisted ventilation & 0 & 0 & 49 & 0 & $49(6.4)$ & & \\
\hline Additional sedative(s) & 24 & 0 & 0 & 0 & $24(3.1)$ & & \\
\hline Anti-emetic & 22 & 0 & 0 & 0 & $22(2.9)$ & & \\
\hline Rapid IV fluids & 0 & 0 & 10 & 0 & $10(1.3)$ & & \\
\hline Antihistamine & 7 & 0 & 0 & 0 & $7(0.9)$ & & \\
\hline Antisialogogue & 0 & 7 & 0 & 0 & $7(0.9)$ & & \\
\hline Laryngeal mask airway & 0 & 0 & 6 & 0 & $6(0.8)$ & & \\
\hline Pressor/epinephrine & 0 & 0 & 0 & 6 & $6(0.8)$ & & \\
\hline Reversal agents & 0 & 0 & 6 & 0 & $6(0.8)$ & & \\
\hline Chest compressions & 0 & 0 & 0 & 5 & $5(0.7)$ & & \\
\hline Tracheal intubation or the administration of & 0 & 0 & 0 & 5 & $5(0.7)$ & & \\
\hline Atropine to treat bradycardia & 0 & 0 & 0 & 4 & $4(0.5)$ & & \\
\hline СРAP & 0 & 0 & 1 & 0 & $1(0.1)$ & & \\
\hline Neuromuscular blockade & 0 & 0 & 1 & 0 & $1(0.1)$ & & \\
\hline Total Intervention Risks & $\begin{array}{c}167 \\
(21.7 \%)\end{array}$ & $\begin{array}{c}457 \\
(59.5 \%)\end{array}$ & $\begin{array}{c}124 \\
(16.1 \%)\end{array}$ & $\begin{array}{c}20 \\
(2.6 \%)\end{array}$ & 768 & & \\
\hline
\end{tabular}


The intervention risks of adverse events are presented in Table 7. There were 768 total interventions associated with the adverse events, with 20 (2.6\%) interventions identified as sentinel: Pressor/epinephrine $(n=6)$, atropine to treat bradycardia $(n=4)$, and chest compressions $(n=5)$. There were $124(16.1 \%)$ moderate interventions: Oral/nasal airway $(n=51)$, bag valve mask (positive pressure ventilation) assisted ventilation $(n=49)$. There were $457(59.5 \%)$ minor interventions: Airway repositioning $(n=183)$, supplemental (new or elevated concentration) oxygen $(n=147)$, and tactile stimulation $(n=120)$. There were $167(21.7 \%)$ minimal interventions; 114 resolved spontaneously without intervention, 24 received additional sedative(s), and 22 received antiemetic.

Adverse events and incidence rates per 10,000 with 95\% CI are presented in Table 7. Oxygen desaturation was separated into categories based on degree and duration. Oxygen desaturation (75-90\%) for $<60$ seconds and airway obstruction represented the most prevalent adverse events, occurring at a rate of 7.8 and 5.42 per 10,000, respectively, followed by apnea at 4.75 per 10,000. Severe $(<75 \%)$ or prolonged $(<90 \%$ for $>60 \mathrm{~s})$ oxygen desaturation occurred at a rate of 3.84 per 10,000 .

All possible sedatives and combinations are available as options on the AE sedation reporting tool. The administration of sedatives (Propofol, Midazolam, Ketamine, Fentanyl, Alfentanil, Chloral hydrate, Clonidine, Dexmedetomidine), alone or in combination, were the most common choices and are summarized in Table 8. Propofol administered alone (18.7\%), Fentanyl in combination with one other drug $(11.9 \%)$, Alfentanil in combination with one other drug $(11.0 \%)$, and Ketamine alone $(8.8 \%)$ are the most common regimens. Other sedatives (Albuterol, Atropine, Dexamethasone, Diazepam, Diphenhydramine, Etomidate, Flumazenil, Fosphenytoin, Fospropofol, Meperidine, Morphine, Naloxone, Nitrous oxide, Remifentanil, Scopolamine, Sevoflurane, Sufentanil) used alone or in combination with other sedatives accounted for $13.76 \%$ of regimens. An association between sedatives and outcomes (sedation risk) was analyzed. There is a statistically significant association between sedatives and sedation risk, exact test $p$-value $<0.0001$. Specific associations between particular sedatives and risks was not able to be evaluated because of the broad spectrum of sedatives and combinations administered, via various routes.

Table 8. Administration of sedatives.

\begin{tabular}{cc}
\hline Sedative Name & Percent \\
\hline Propofol alone & 18.74 \\
\hline Other $^{*}$ & 13.76 \\
\hline Fentanyl w/one other drug & 11.86 \\
\hline Alfentanil w/one other drug & 11.03 \\
\hline Ketamine alone & 8.78 \\
\hline Ketamine w/ $\geq 2$ other drugs & 7.59 \\
\hline Ketamine w/one other drug & 7.12 \\
\hline Propofol w/one other drug & 5.22 \\
\hline Fentanyl w/ $\geq 2$ other drugs & 3.32 \\
\hline Midazolam alone & 3.32 \\
\hline Dexmedetomidine w/one other drug & 2.14 \\
\hline Midazolam w/one other drug & 1.30 \\
\hline
\end{tabular}


Table 8. Cont.

\begin{tabular}{cc}
\hline Sedative Name & Percent \\
\hline Clonidine alone & 1.07 \\
\hline Alfentanil w/ $\geq 2$ or more drugs & 0.83 \\
\hline Midazolam w/ $\geq 2$ other drugs & 0.83 \\
\hline Chloral hydrate alone & 0.71 \\
\hline Chloral hydrate w/one other drug & 0.71 \\
\hline Fentanyl alone & 0.71 \\
\hline Alfentanil alone & 0.36 \\
\hline Dexmedetomidine w/ $\geq 2$ other drugs & 0.36 \\
\hline Chloral hydrate w/ $\geq 2$ other drugs & 0.24 \\
\hline Clonidine w/one other drug & 0.00 \\
\hline Clonidine w/ $\geq 2$ other drugs & 0.00 \\
\hline Dexmedetomidine alone & 0.00 \\
\hline Propofol w/ $\geq 2$ other drugs & 0.00 \\
\hline
\end{tabular}

* Other represents the following drugs alone and in combination with other drugs: Albuterol, Atropine, Dexamethasone, Diazepam, Diphenhydramine, Etomidate, Flumazenil, Fosphenytoin, Fospropofol, Meperidine, Morphine, Naloxone, Nitrous oxide, Remifentanil, Scopolamine, Sevoflurane, Sufentanil.

\section{Discussion}

Creating, implementing, and updating quality improvement data in a collaborative manner has become an important initiative of all published sedation guidelines worldwide. The collection of outcomes is not limited only to deep sedation or monitored anesthesia care, but also extends even to moderate depths of sedation. To date, all published outcome data has represented retrospective reviews of outcome data collected by specific groups of sedation providers, usually representing a single specialty, sedative agent, patient population (adults or children), and occasionally representing a group of varied specialists $[2,6,22,37-47]$. The data has almost always represented either pediatrics or adult patients, never representing sedation in both populations across continents.

This report has highlighted that with multi-specialty providers from a diverse background administering to the extreme spectrums of age for a variety of procedures, the overall risk of sedation is moderate. Almost $15 \%$ of all adverse events do not require any intervention. The majority of interventions, when required, are minor and involve airway repositioning most commonly for oxygen desaturation, airway obstruction, or apnea. When sentinel outcomes do occur, they are most likely to involve cardiac arrest, cardiovascular collapse, or oxygen desaturations $<75 \%$. Propofol and ketamine delivered as sole agents, are most common with intravenous route strongly favored. Most providers deliver either to adults or children, with only a minority delivering to both populations. In-hospital sedation in the academic setting tends to be more common. The increased risk with higher ASA status is consistent with prior published studies $[5,13,48,49]$. The findings of higher risks between $6 \mathrm{pm}$ and 6 $\mathrm{AM}$ and for those sedations which were for emergent procedures have not previously been reported and warrant further investigation.

The limitations of our study are those shared by all quality assurance and database reports. The data represents only that of the sedation providers who input data. The sedationist makes his/her own determination whether to enter a sedation encounter into the adverse event reporting tool. Each provider may have his/her own threshold and criteria for entering data. As the website is open access and free-of-charge, it is not possible to surmise the rationale of different providers. The intent of the online tool is for sedation providers to tailor its use to his/her particular needs. The tool does not require HIPAA identifiers and the data is collected anonymously (users identity only known to the tool administrator (KPM), all with the intent to encourage "unintimidated" reporting. It is also possible 
that not every adverse event which occurred during this time period is captured. This is a limitation of all database reports. Particularly as sedation is not commonly captured by electronic medical records, often performed by multi-specialists, the data is unavailable to be extricated electronically. In under-developed areas, electronic medical records are often unavailable and non-existent. Even the most sophisticated of electronic records are unable to accurately capture all events: They may be able to capture physiological vital signs, but fail to document the interventions performed and never are able to record the outcomes.

This database is completely founded on clinician self-report and, thus, risks under-reporting of adverse events. There are multiple etiologies for under-reporting: Sedationists may not want to appear to be "poorly performing" by reporting adverse events, some institutions may have policies in place that may generate "punitive" reactions to documented adverse events (e.g., initiating root cause analysis proceedings) and others may simply forget to document the adverse event in the course of providing clinical care because it is not routine practice to use this tool on a regular basis. Thus, the self-reporting of the adverse event reporting tool differentiates this database from others which implement more comprehensive approaches to maximize capture and review of all data. For example, some databases require entry of consecutive cases, ongoing database surveillance, manual audits of randomly selected charts, automated validation checks of their data, and review of interrater reliability prior to data collection and on an ongoing basis.

Brief events (oxygen desaturation, hypotension, tachycardia, bradycardia, decreased respiratory rate) may not be captured even by electronic medical records, depending on how frequently these events are recorded. Typically, vital signs and physiological parameters are reported every $5 \mathrm{~min}$. Thus, occurrences within this 5 min window may often go unreported, even electronically. As with any database collecting system, there is a tendency for the reporters to be a self-selected group of individuals who are likely to have some special interest in sedation. Thus, it is possible that these outcomes may not mirror the clinical practice of sedation as a whole.

The advantage of the AE reporting tool is that it is the only online, open access, and free-of-charge site that allows providers to not only input their data but also be able to follow and track their own outcomes. Any provider with access to the internet has the ability to report and collect their sedation outcomes. Free of HIPAA identifiers, the user is able to collect data but also still be able to query a particular record if some of the basic specifics of the procedure or event are known. This ability makes the $\mathrm{AE}$ tool unique and invaluable to providers, particularly those who lack an organized infrastructure needed to record and collect data as obliged by the Joint Commission and International Joint Commission. The AE tool importantly ensures that all data points are collected, because the user is unable to proceed to the following queries and to complete the data input, unless all data is entered. As adverse events tend to be memorable, as are the associated interventions and outcomes, we believe and assume that those who enter the data have a clear recollection of the event and, often, probably are referring to the patient's medical records as demographics are included (age, sedatives, routes of administration, etc.). The database is unusual because a significant proportion of the data includes dental sedation.

The adverse event sedation reporting tool as well as this report, represents the monolithic effort of multi-specialty providers from six continents to identify and classify their sedation related outcomes, using definitions that have been standardized and adopted for clinical and research purposes. Our report of an increased risk of adverse events in ASA three or higher, evening sedations, the middle age and elderly adult, and out of hospital procedures, are revealing first steps to guide future studies of sedation-outcome, as well as the design of sedation services.

Author Contributions: Reviewing the relevant literature, K.P.M., M.G.R., and S.M.G.; Manuscript preparation, K.P.M., M.G.R., D.C., N.S., L.F., D.G., F.V., D.C., and S.M.G.; Approval of final manuscript and attestation to data integrity, K.P.M., M.G.R., D.C., N.S., L.F., D.G., F.V., D.C., and S.M.G.

Funding: Adverse event sedation reporting tool is self-supported through Boston Children's Hospital departmental funds. 
Acknowledgments: The authors acknowledge Kimberly Manning, BA, Department of Anesthesiology, Critical Care and Pain Medicine at Boston Children's Hospital, Boston, MA for her highly valued assistance in the preparation of this manuscript.

Conflicts of Interest: The authors declare no conflict of interest.

\section{References}

1. Pambianco, D.J.; Vargo, J.J.; Pruitt, R.E.; Hardi, R.; Martin, J.F. Computer-assisted personalized sedation for upper endoscopy and colonoscopy: A comparative, multicenter randomized study. Gastrointest. Endosc. 2011, 73, 765-772. [CrossRef]

2. Wadhwa, V.; Issa, D.; Garg, S.; Lopez, R.; Sanaka, M.R.; Vargo, J.J. Similar Risk of Cardiopulmonary Adverse Events Between Propofol and Traditional Anesthesia for Gastrointestinal Endoscopy: A Systematic Review and Meta-analysis. Clin. Gastroenterol. Hepatol. 2017, 15, 194-206. [CrossRef]

3. Davidovich, E.; Meltzer, L.; Efrat, J.; Gozal, D.; Ram, D. Post-Discharge Events Occurring after Dental Treatment under Deep Sedation in Pediatric Patients. J. Clin. Pediatr. Dent. 2017, 41, 232-235. [CrossRef]

4. Srinivasan, M.; Turmelle, M.; Depalma, L.M.; Mao, J.; Carlson, D.W. Procedural sedation for diagnostic imaging in children by pediatric hospitalists using propofol: Analysis of the nature, frequency, and predictors of adverse events and interventions. J. Pediatr. 2012, 160, 801-806. [CrossRef]

5. Srinivasan, M.; Carlson, D.W. Procedural sedation by pediatric hospitalists: Analysis of the nature and incidence of complications during ketamine and nitrous oxide sedation. Hosp. Pediatr. 2013, 3, 342-347. [CrossRef]

6. Biber, J.L.; Allareddy, V.; Allareddy, V.; Gallagher, S.M.; Couloures, K.G.; Speicher, D.G.; Cravero, J.P.; Stormorken, A.G. Prevalence and Predictors of Adverse Events during Procedural Sedation Anesthesia-Outside the Operating Room for Esophagogastroduodenoscopy and Colonoscopy in Children: Age Is an Independent Predictor of Outcomes. Pediatr. Crit. Care Med. 2015, 16, e251-e259. [CrossRef]

7. Tsze, D.S.; Mallory, M.D.; Cravero, J.P. Practice Patterns and Adverse Events of Nitrous Oxide Sedation and Analgesia: A Report from the Pediatric Sedation Research Consortium. J. Pediatr. 2016, 169, 260-265. [CrossRef] [PubMed]

8. Grunwell, J.R.; Travers, C.; Stormorken, A.G.; Scherrer, P.D.; Chumpitazi, C.E.; Stockwell, J.A.; Roback, M.G.; Cravero, J.; Kamat, P.P. Pediatric Procedural Sedation Using the Combination of Ketamine and Propofol Outside of the Emergency Department: A Report from the Pediatric Sedation Research Consortium. Pediatr. Crit. Care Med. 2017, 18, e356-e363. [CrossRef] [PubMed]

9. Green, S.M.; Roback, M.G.; Krauss, B.; Brown, L.; McGlone, R.G.; Agrawal, D.; McKee, M.; Weiss, M.; Pitetti, R.D.; Hostetler, M.A.; et al. Predictors of airway and respiratory adverse events with ketamine sedation in the emergency department: An individual-patient data meta-analysis of 8282 children. Ann. Emerg. Med. 2009, 54, 158-168. [CrossRef] [PubMed]

10. Riphaus, A.; Macias-Gomez, C.; Deviere, J.; Dumonceau, J.M. Propofol, the preferred sedation for screening colonoscopy, is underused. Results of an international survey. Dig. Liver Dis. 2012, 44, 389-392. [CrossRef]

11. Chicka, M.C.; Dembo, J.B.; Mathu-Muju, K.R.; Nash, D.A.; Bush, H.M. Adverse events during pediatric dental anesthesia and sedation: A review of closed malpractice insurance claims. Pediatr. Dent. 2012, 34 , 231-238. [PubMed]

12. Lee, H.H.; Milgrom, P.; Starks, H.; Burke, W. Trends in death associated with pediatric dental sedation and general anesthesia. Paediatr. Anaesth. 2013, 23, 741-746. [CrossRef] [PubMed]

13. Frieling, T.; Heise, J.; Kreysel, C.; Kuhlen, R.; Schepke, M. Sedation-associated complications in endoscopy-Prospective multicentre survey of 191,142 patients. Z. Gastroenterol. 2013, 51, 568-572. [CrossRef] [PubMed]

14. Sanborn, P.A.; Michna, E.; Zurakowski, D.; Burrows, P.E.; Fontaine, P.J.; Connor, L.; Mason, K.P. Adverse cardiovascular and respiratory events during sedation of pediatric patients for imaging examinations. Radiology 2005, 237, 288-294. [CrossRef] [PubMed]

15. Mason, K.P.; Robinson, F.; Fontaine, P.; Prescilla, R. Dexmedetomidine offers an option for safe and effective sedation for nuclear medicine imaging in children. Radiology 2013, 267, 911-917. [CrossRef] [PubMed] 
16. Mason, K.P.; Zgleszewski, S.; Forman, R.E.; Stark, C.; DiNardo, J.A. An exaggerated hypertensive response to glycopyrrolate therapy for bradycardia associated with high-dose dexmedetomidine. Anesth. Analg. 2009, 108, 906-908. [CrossRef] [PubMed]

17. Mason, K.P.; Zgleszewski, S.E.; Dearden, J.L.; Dumont, R.S.; Pirich, M.A.; Stark, C.D.; D'Angelo, P.; Macpherson, S.; Fontaine, P.J.; Connor, L.; et al. Dexmedetomidine for pediatric sedation for computed tomography imaging studies. Anesth. Analg. 2006, 103, 57-62. [CrossRef]

18. Mahmoud, M.; Jung, D.; Salisbury, S.; McAuliffe, J.; Gunter, J.; Patio, M.; Donnelly, L.F.; Fleck, R. Effect of increasing depth of dexmedetomidine and propofol anesthesia on upper airway morphology in children and adolescents with obstructive sleep apnea. J. Clin. Anesth. 2013, 25, 529-541. [CrossRef]

19. Wu, J.; Mahmoud, M.; Schmitt, M.; Hossain, M.; Kurth, D. Comparison of propofol and dexmedetomedine techniques in children undergoing magnetic resonance imaging. Paediatr. Anaesth. 2014, 24, 813-818. [CrossRef]

20. Spera, A.L.; Saxen, M.A.; Yepes, J.F.; Jones, J.E.; Sanders, B.J. Office-Based Anesthesia: Safety and Outcomes in Pediatric Dental Patients. Anesth. Prog. 2017, 64, 144-152. [CrossRef]

21. Bennett, J.D.; Kramer, K.J.; Bosack, R.C. How safe is deep sedation or general anesthesia while providing dental care? J. Am. Dent. Assoc. 2015, 146, 705-708. [CrossRef] [PubMed]

22. Vargo, J.J.; Niklewski, P.J.; Williams, J.L.; Martin, J.F.; Faigel, D.O. Patient safety during sedation by anesthesia professionals during routine upper endoscopy and colonoscopy: An analysis of 1.38 million procedures. Gastrointest. Endosc. 2017, 85, 101-108. [CrossRef] [PubMed]

23. Riphaus, A.; Geist, F.; Wehrmann, T. Endoscopic sedation and monitoring practice in Germany: Re-evaluation from the first nationwide survey 3 years after the implementation of an evidence and consent based national guideline. Z. Gastroenterol. 2013, 51, 1082-1088. [CrossRef] [PubMed]

24. Rex, D.K.; Deenadayalu, V.P.; Eid, E.; Imperiale, T.F.; Walker, J.A.; Sandhu, K.; Clarke, A.C.; Hillman, L.C.; Horiuchi, A.; Cohen, L.B.; et al. Endoscopist-directed administration of propofol: A worldwide safety experience. Gastroenterology 2009, 137, 1229-1237. [CrossRef] [PubMed]

25. Mason, K.P.; Green, S.M.; Piacevoli, Q. Adverse event reporting tool to standardize the reporting and tracking of adverse events during procedural sedation: A consensus document from the World SIVA International Sedation Task Force. Br. J. Anaesth. 2012, 108, 13-20. [CrossRef]

26. Newstead, B.; Bradburn, S.; Appelboam, A.; Reuben, A.; Harris, A.; Hudson, A.; Jones, L.; McLauchlan, C.; Riou, P.; Jadav, M.; et al. Propofol for adult procedural sedation in a UK emergency department: Safety profile in 1008 cases. Br. J. Anaesth. 2013, 111, 651-655. [CrossRef]

27. Brown, C.A., 3rd; Bair, A.E.; Pallin, D.J.; Walls, R.M. Techniques, success, and adverse events of emergency department adult intubations. Ann. Emerg. Med. 2015, 65, 363-370.e1. [CrossRef]

28. Homfray, G.; Palmer, A.; Grimsmo-Powney, H.; Appelboam, A.; Lloyd, G. Procedural sedation of elderly patients by emergency physicians: A safety analysis of 740 patients. Br. J. Anaesth. 2018, 121, 1236-1241. [CrossRef]

29. Kidd, L.R.; Lyons, S.C.; Lloyd, G. Paediatric procedural sedation using ketamine in a UK emergency department: A 7 years review of practice. Br. J. Anaesth. 2016, 116, 518-523. [CrossRef]

30. Smits, G.J.; Kuypers, M.I.; Mignot, L.A.; Reijners, E.P.; Oskam, E.; Van Doorn, K.; Thijssen, W.A.; Korsten, E.H. Procedural sedation in the emergency department by Dutch emergency physicians: A prospective multicentre observational study of 1711 adults. Emerg. Med. J. 2017, 34, 237-242. [CrossRef]

31. Kaye, P.; Govier, M. Procedural sedation with propofol for emergency DC cardioversion. Emerg. Med. J. 2014, 31, 904-908. [CrossRef] [PubMed]

32. Mason, K.P. World SIVA: The pediatric initiative. Paediatr. Anaesth. 2010, 20, 209-210. [CrossRef] [PubMed]

33. Dewdney, C.; MacDougall, M.; Blackburn, R.; Lloyd, G.; Gray, A. Capnography for procedural sedation in the ED: A systematic review. Emerg. Med. J. 2017, 34, 476-484. [CrossRef] [PubMed]

34. Koers, L.; Eberl, S.; Cappon, A.; Bouwman, A.; Schlack, W.; Hermanides, J.; Preckel, B. Safety of moderate-to-deep sedation performed by sedation practitioners: A national prospective observational study. Eur. J. Anaesthesiol. 2018, 35, 659-666. [CrossRef] [PubMed]

35. Papineni McIntosh, A.; Ashley, P.F.; Lourenco-Matharu, L. Reported side effects of intravenous midazolam sedation when used in paediatric dentistry: A review. Int. J. Paediatr. Dent. 2015, 25, 153-164. [CrossRef] [PubMed] 
36. Early, D.S.; Lightdale, J.R.; Vargo, J.J., 2nd; Acosta, R.D.; Chandrasekhara, V.; Chathadi, K.V.; Evans, J.A.; Fisher, D.A.; Fonkalsrud, L.; Hwang, J.H.; et al. Guidelines for sedation and anesthesia in GI endoscopy. Gastrointest. Endosc. 2018, 87, 327-337. [CrossRef]

37. Sulton, C.; McCracken, C.; Simon, H.K.; Hebbar, K.; Reynolds, J.; Cravero, J.; Mallory, M.; Kamat, P. Pediatric Procedural Sedation Using Dexmedetomidine: A Report from the Pediatric Sedation Research Consortium. Hosp. Pediatr. 2016, 6, 536-544. [CrossRef]

38. Couloures, K.G.; Beach, M.; Cravero, J.P.; Monroe, K.K.; Hertzog, J.H. Impact of provider specialty on pediatric procedural sedation complication rates. Pediatrics 2011, 127, e1154-e1160. [CrossRef]

39. Vargo, J.J.; Zuccaro, G., Jr.; Dumot, J.A.; Shermock, K.M.; Morrow, J.B.; Conwell, D.L.; Trolli, P.A.; Maurer, W.G. Gastroenterologist-administered propofol versus meperidine and midazolam for advanced upper endoscopy: A prospective, randomized trial. Gastroenterology 2002, 123, 8-16. [CrossRef]

40. AOMRC. Safe Sedation Practice for Healthcare Procedures; AOMRC: London, UK, 2013.

41. Cote, C.J.; Wilson, S. Guidelines for Monitoring and Management of Pediatric Patients Before, during, and After Sedation for Diagnostic and Therapeutic Procedures: Update 2016. Pediatrics 2016, 138, 13E-39E. [CrossRef]

42. Apfelbaum, J.; Gross, J.B.; Connis, R.T.; Agarkar, M.; Arnold, D.E.; Coté, C.J.; Tung, A. Practice Guidelines for Moderate Procedural Sedation and Analgesia 2018A Report by the American Society of Anesthesiologists Task Force on Moderate Procedural Sedation and Analgesia, the American Association of Oral and Maxillofacial Surgeons, American College of Radiology, American Dental Association, American Society of Dentist Anesthesiologists, and Society of Interventional Radiology*. Anesthesiology 2018, 128, 437-479. [CrossRef]

43. Buxbaum, J.; Roth, N.; Motamedi, N.; Lee, T.; Leonor, P.; Salem, M.; Gibbs, D.; Vargo, J. Anesthetist-Directed Sedation Favors Success of Advanced Endoscopic Procedures. Am. J. Gastroenterol. 2017, 112, 290-296. [CrossRef] [PubMed]

44. Bhatt, M.; Roback, M.G.; Joubert, G.; Farion, K.J.; Ali, S.; Beno, S.; McTimoney, C.M.; Dixon, A.; Dubrovsky, A.S.; Barrowman, N.; et al. The design of a multicentre Canadian surveillance study of sedation safety in the paediatric emergency department. BMJ Open 2015, 5, e008223. [CrossRef] [PubMed]

45. Kannikeswaran, N.; Lieh-Lai, M.; Malian, M.; Wang, B.; Farooqi, A.; Roback, M.G. Optimal dosing of intravenous ketamine for procedural sedation in children in the ED-a randomized controlled trial. Am. J. Emerg. Med. 2016, 34, 1347-1353. [CrossRef] [PubMed]

46. Litman, R.S. The Use of Patient Registries to Detect Risk Factors of Anesthesia and Sedation Complications. Pediatrics 2016, 137, e20154579. [CrossRef] [PubMed]

47. West, S.K.; Griffiths, B.; Shariff, Y.; Stephens, D.; Mireskandari, K. Utilisation of an outpatient sedation unit in paediatric ophthalmology: Safety and effectiveness of chloral hydrate in 1509 sedation episodes. $\mathrm{Br}$. J. Ophthalmol. 2013, 97, 1437-1442. [CrossRef]

48. Habre, W.; Disma, N.; Virag, K.; Becke, K.; Hansen, T.G.; Johr, M.; Leva, B.; Morton, N.S.; Vermeulen, P.M.; Zielinska, M.; et al. Incidence of severe critical events in paediatric anaesthesia (APRICOT): A prospective multicentre observational study in 261 hospitals in Europe. Lancet Respir. Med. 2017, 5, 412-425. [CrossRef]

49. Brown, C.H.; Azman, A.S.; Gottschalk, A.; Mears, S.C.; Sieber, F.E. Sedation depth during spinal anesthesia and survival in elderly patients undergoing hip fracture repair. Anesth. Analg. 2014, 118, 977-980. [CrossRef]

(C) 2019 by the authors. Licensee MDPI, Basel, Switzerland. This article is an open access article distributed under the terms and conditions of the Creative Commons Attribution (CC BY) license (http://creativecommons.org/licenses/by/4.0/). 